\title{
Assessing the productivity of technology transfer offices: An analysis of the relevance of aspiration performance and portfolio complexity
}

\author{
Esteban Lafuente ${ }^{1}$ \\ Department of Management, Universitat Politècnica de Catalunya (Barcelona Tech) \\ EPSEB, Av. Gregorio Marañón, 44-50, 3era planta. 08028. Barcelona. Spain \\ Email: esteban.lafuente@upc.edu
}

\section{Jasmina Berbegal-Mirabent}

Department of Economy and Business Organization, Universitat Internacional de Catalunya C. Immaculada, 22. 08017. Barcelona, Spain

Email: jberbegal@uic.es

Paper published in the Journal of Technology Transfer. Please cite as:

Lafuente, E., Berbegal-Mirabent, J. (2017). Assessing the productivity of technology transfer offices: an analysis of the relevance of aspiration performance and portfolio complexity. Journal of Technology Transfer, in press, doi: 10.1007/s10961-017-9604-х

Acknowledgements: For their ideas and insightful comments that helped us to improve the paper we are grateful to Tommaso Agasisti (Politecnico di Milano School of Management) and seminar participants at the 4th Workshop on Efficiency in Education (2016). Esteban Lafuente acknowledges financial support from the Spanish Ministry of Science and Innovation (Grant number: ECO2013-48496-C4-4-R).

\footnotetext{
${ }^{1}$ Corresponding author
} 


\title{
Assessing the productivity of technology transfer offices: An analysis of the relevance of aspiration performance and portfolio complexity
}

\begin{abstract}
:
The paper investigates the productivity level of technology transfer offices (TTOs) affiliated to Spanish public universities. The proposed approach allows the development of a framework that matches universities' technology transfer concerns with the need to accurately analyze the role of the outcome configuration of technology transfer offices (TTOs). We analyze the productivity of Spanish TTOs during 2006-2011 by computing total factor productivity models rooted in non-parametric techniques, namely the Malmquist index. The results confirm that technology transfer productivity is affected by changes in the configuration of the TTO's outcome portfolio that result from benchmarking own and market peers' performance levels. While benchmarking own performance levels facilitates the exploitation of internal resources and yields superior productivity results, changes in TTO's portfolio based on comparisons with market peers might generate greater operational costs that negatively impact productivity.
\end{abstract}

Keywords: Technology transfer, technology transfer office, universities, total factor productivity, data envelopment analysis, aspiration performance

JEL classification: I23, J48 


\section{Assessing the productivity of technology transfer offices: An analysis of the relevance of aspiration performance and portfolio complexity}

\section{Introduction}

Universities are organizations that perform a key role within contemporary societies by educating large proportions of the population and generating various forms of valuable knowledge. Recently, often on the initiative of policy-makers, many universities have taken action to develop a 'third mission' by fostering links with knowledge users and facilitating technology transfer (Etzkowitz et al. 2000; Dill 2014). Governments have traditionally channeled considerable resources to finance scientific outcomes and technology transfer activities, either through tax policy or direct investment. Additionally, the growing awareness of the importance of knowledge transfer activities as key pillars for the consolidation of knowledge-based economies has led European governing bodies to adopt specific policies within the EU 2020 strategic plan aimed at stimulating knowledge creation and diffusion, as well as scientific productivity among universities (European Commission 2015).

The increased emphasis on the commercialization of technology transfer outcomes to the private sector has stimulated many universities to create Technology Transfer Offices (TTOs). TTOs can be seen as knowledge brokers that encourage technology transfer processes from academia to industry by bringing together scientists, businesses and venture capitalists (Friedman and Silberman 2003; Macho-Stadler et al. 2007; Sellenthin 2009).

From an organizational perspective, TTOs are separate units created within universities whose primary role relates to the management of technology transfer processes. Nevertheless, TTOs do not materialize the generally positive outcomes of their technology transfer efforts at the same intensity. The outputs of technology transfer - i.e., spinoffs, licenses, and patents - are not only heterogeneous between TTOs, but also in terms of the factors explaining variations in TTOs' productivity over time. TTOs are challenged with the need to harmonize scientists' interests - who often prioritize their scientific productivity - with the exploitation of their resources to transfer the new knowledge generated within the university to the industry. A common presumption is that TTOs must maximize their outcomes. Yet, different resources, abilities and internal processes are necessary to generate technology transfer outcomes. Additionally, TTOs' performance may be affected by resource allocation policies and by strategic choices linked to the TTO's outcome portfolio that are not necessarily conducive to technology transfer outputs.

This is the focus of this study. More concretely, we evaluate the technology transfer efficiency of Spanish TTOs via total factor productivity models rooted in non-parametric techniques (Malmquist index). Additionally, we explore the role on TTOs' productivity of 
strategic choices linked to changes in the configuration of the TTO's technology transfer portfolio based on the benchmarking of own and other TTOs performance aspiration levels.

The empirical application considers the TTOs affiliated to Spanish public universities between 2006 and 2011. This setting is attractive because, similar to other European countries, Spain has undergone significant reforms in the university's regulatory framework seeking to parameterize technology transfer outcomes and enhance publicly funded technology transfer activities (Caldera and Debande 2010; Lafuente and Berbegal-Mirabent 2017). This implies drastic modifications in the universities' strategic model in which TTOs play a key role. The Spanish setting offers the opportunity to analyze how TTOs capitalize on their resources seeking to produce technology transfer outcomes in a context in which information availability gives TTOs strong incentives to benchmark their own and other TTOs seeking to introduce changes that might enhance their productivity levels.

Notwithstanding the increased relevance of transferring technology generated within universities to the industry for policy makers and universities, the majority of work has analyzed technology transfer performance from a university perspective (e.g., Thursby and Thursby 2002; Clarysse et al. 2005; Caldera and Debande 2010; Berbegal-Mirabent et al. 2013), while few articles have specifically dealt with the functioning of TTOs from a theoretical (e.g., MachoStadler et al. 2007) or empirical perspective (e.g., Siegel et al. 2003; Chappel et al. 2005).

The analysis of the relationship between benchmarking and changes in the strategic orientation of TTOs has been largely sidelined in prior research. TTOs are not monolithic organizations and we argue that performance feedback triggers different strategies that materialize in changes in the configuration of TTOs' outputs, and that these strategic changes impact TTOs' productivity.

In this sense, this paper contributes to the literature in two main ways. First, the main contribution of this work is to analyze the TTO's adaptive behavior through aspirationperformance feedback models. By drawing from the organizational theory literature (e.g., Levinthal and March 1981; Labianca et al. 2009), the proposed analysis allows us to evaluate how benchmark-driven strategic change impacts TTOs' productivity. We propose that TTOs benchmark their own past record and other peers, and that this valuable information motivates change in the strategic orientation of TTOs' output portfolio. By explicitly linking aspirationperformance feedback with productivity patterns, this study answers the call made by Siegel et al. (2007) and Fitzgerald and Cunningham (2016) for more research on the relationship between the strategy making of TTOs and performance. Our results suggesting that enhanced productivity follows organizational change based on the evaluation of the TTOs' own historical record contribute to better understand how performance feedback impacts TTOs' strategic actions and, consequently, subsequent productivity. 
Additionally, this study extends the rich literature on the technology transfer performance of publicly funded organizations (see, e.g., Feldman et al. 2002; Thursby and Kemp 2002; Clarysse et al. 2005; Siegel et al. 2007; Sellenthin 2009; Caldera and Debande 2010; Algieri et al. 2013; Berbegal-Mirabent et al. 2013; Kim 2013; Vinig and Lips 2015). The analysis of the role of resource specialization on TTO's performance has been mostly unaddressed in previous empirical research (e.g., Chappel et al., 2005; Anderson et al. 2007). Thus, a second contribution of this study is to measure TTOs' productivity patterns via a modeling strategy that accurately reflects TTOs' technology by integrating specific inputs linked to the workforce specialization in the efficiency analysis.

The reminder of the paper is organized as follows. Section 2 presents the theoretical underpinning. Section 3 presents the main characteristics of the Spanish university system. Section 4 describes the data and the methodological approach, while Section 5 offers the empirical results. In Section 6 the discussion is presented, and the final section provides the concluding remarks, implications and future research lines.

\section{Background theory}

\subsection{Knowledge generation and the reconciling role of technology transfer offices}

The rise of the knowledge-based economy in advanced countries has attracted increased attention on the creation and commercialization of knowledge generated within universities via different mechanisms (patents, licensing contracts, and the creation of university-based spinoffs). In recent decades, existing organizations - most notably universities - have witnessed a major change in their role and they are now submitted to new challenges as society advances in science and technology (Dill 2014). In this context, many voices have claimed for a deeper involvement of universities with various stakeholders via a closer association between industry and science (Perkmann et al. 2013). The universities' third mission - interaction with surrounding stakeholders-implies the provision of new knowledge, experience and technological solutions to industry demands (Schattock 2009).

University research can spur business innovation, foster competitiveness, and promote economic development (Algieri et al. 2013). The institutional changes underwent by universities have increased the incentives to remain at the cutting-edge of research, recruit highly skilled human capital, and develop appropriate mechanisms and infrastructures to accelerate the valorization process of knowledge. Accordingly, there is a large body of research assessing the drivers and outcomes of technology transfer at the university level (Thursby and Thursby 2002; Clarysse et al. 2005; Anderson et al. 2007; Caldera and Debande 2010; Berbegal-Mirabent et al. 2013; Kim 2013; Hsu et al. 2015; Agasisti and Wolszczak-Derlacz 2015).

The increased emphasis on transferring technology to the private sector for commercialization has led many universities to create new organizational forms-Technology 
Transfer Offices (TTOs) — to legitimize their commercial activities (Siegel et al. 2007). Starting in the US in the 1980s but rapidly expanding to other countries, TTOs have been included in universities' organizational structure as independent units whose primary objective is to bring together academics, businesses and venture capitalists, and promote knowledge transfer from academia to industry (Algieri et al. 2013). The role of TTOs mostly consists of spreading an entrepreneurial culture of research, encourage the dissemination of scientific outcomes and support scholars through the stages of research commercialization (Caldera and Debande, 2010). Also, by employing its recourses to build strong networks the TTO contributes to reduce barriers between scientists and industry (Friedman and Silberman 2003).

Knowledge is disseminated and commercialized in the form of scientific publications, license contracts or patents. Research outcomes can also be the starting point for the creation of a new venture. Technology transfer activities and scientific excellence are mutually reinforcing (Baldini 2009); however, previous studies show that this process has taken place at different rates and intensities (Shattock 2009), and that these transformations are highly tied with the strategic vision of each TTO. Although the increased usability of university innovations by industry (Kim 2013), the commercialization of knowledge generated within universities is hard and certain discrepancies between academia and industry might affect this process.

First, universities and industry have different objectives. While market-oriented firms prioritize research low in riskiness with direct marketability, public universities mostly focus on the development of projects with a longer time horizon and uncertain commercial applications (Di Gregorio and Shane 2003). Second, a discrepancy exists on how to capitalize new knowledge. Scholars mostly facilitate the diffusion of new knowledge as a public good by fully disclosing work methods and results linked to the new knowledge. On contrary, businesses seek to secure the control of intellectual property and the potential future rents resulting from the new knowledge. Additionally, scientists have strong incentives to share their research as quickly as possible via scientific publications, while the industry is interested in delaying the publication process to keep scientific results with potential economic value hidden (Anderson et al. 2007).

Third, prior research shows that scientists' dissimilar involvement in technology transfer might result from a weak system of incentives (Siegel et al. 2007). Universities often evaluate faculty on the basis of systems that link a successful academic career to valuable research accomplishments, which sways scholars to produce academically rigorous research and develop research networks (Lafuente and Berbegal-Mirabent 2017). Thus, many scientists lack the skills and abilities both to engage in commercial activities and create or develop universityindustry collaborations (Perkmann and Walsh 2009), and may explain the highly skewed distribution of successful commercialization among universities (Vinig and Lips 2015).

A growing literature stream has evaluated why some TTOs are more successful than others in commercializing research outcomes (see e.g., Anderson et al. 2007; Wright et al. 
2007). Results are inconclusive. Notwithstanding the diverse and complex attributions of TTOs complicate the creation of accurate metrics to capture their performance (Perkman et al. 2013; Hsu et al. 2015); it seems that organizational practices and resource allocation strategies explain a significant proportion of the variation of TTOs' performance (Anderson et al. 2007; Siegel et al. 2007; Balsmeier and Pellens 2014).

Within TTOs, scientists are the suppliers of valuable and potentially marketable knowledge (Siegel et al. 2007). The transfer of knowledge and technology from university to industry appears in a myriad of forms that include formal (i.e., patents, $R \& D$ contracts, licenses, spin-offs) and informal (i.e. personal contacts, industry-science networks, cooperation in education) outcomes.

From an organizational perspective, the biggest challenge for TTOs is to harmonize the elements of their production function, including scientists - who often pursue scientific productivity — and their specific resources - i.e., staff specialized in knowledge-transfer activities and administrative support staff - to effectively exploit the knowledge generated within the university. Underlying prior research analyses is the assumption that TTOs must maximize their technology transfer outcomes (Anderson et al. 2007). Nevertheless, different resources, abilities and internal processes are necessary to produce the various TTO outcomes; and TTOs' performance might be affected by both the allocation of resources and strategic choices that are not always conducive to the TTO outputs.

In a context where strategic choices condition TTOs' performance, variations in the configuration of the TTO's portfolio might result from the performance evaluation of the TTOs' own historical records as well as from the benchmarking of other TTOs' actions. The policy significance of this issue lies in the need to gain insights into the value of the TTOs' outcomes currently being pursued by exploiting their resources. Such outcomes are the consequence of TTOs' efforts for encouraging technology transfer in the expectation of the benefits that will accrue to both academia and industry. Given the ambiguous results in the literature, it seems worthwhile to analyze the conditions under which TTOs generate these benefits as well as how benchmark analysis affects the TTOs' strategy making.

\subsection{Aspiration performance and the strategic choices of technology transfer offices (TTOs)}

The success of technology transfer activities depends heavily on the work of the TTO. In the case of TTOs, the efficient commercialization of inventions requires high specific investments, the creation of efficient organizational structures and the recruiting of highly skilled staff. But, do TTOs strive for enhanced performance? Do decision-makers evaluate the TTO's success or failure by benchmarking their own past records or other peers (i.e., TTOs)?

Existing research specifically addressing technology transfer performance has mostly analyzed the effect of variables linked to university inputs (e.g., university size and experience, 
faculty, research orientation of the university) and various factors related to the TTO (e.g., staff, budget, and experience) (Thursby and Kemp 2002; Siegel et al. 2003; Chapple et al. 2005; Sellenthin 2009; Berbegal-Mirabent et al. 2013; Vinig and Lips 2015).

From an organizational perspective, the success or failure in achieving the set outcomes affects managers' willingness to introduce change (Levitt and March 1988). In this sense, performance feedback becomes a potentially critical element that may contribute to understand the conditions under which organizations alter their practices or strategies. Nevertheless, the analysis of the relationship between benchmarking activities, changes in the strategic orientation of the TTO and technology transfer performance remains unaddressed.

Building on insights from organizational theory, organizational change is primarily driven by discrepancies between the organization's performance aspirations and the feedback it receives in terms of its performance (Baum and Dahlin 2007; Levitt and March 1988).

Performance-feedback theorists argue that businesses initiate change when they are dissatisfied with their expected or aspired-to performance level. An aspiration level is a reference point that simplifies performance evaluation by transforming business-specific outcome metrics into more informative measures of success or failure. Aspiration levels arise from comparisons against two reference points that decision makers use to evaluate their own current performance: the organization's own historical performance and performance of the organization's peer group (Levinthal and March 1981; Labianca et al. 2009).

By definition, TTOs are catalysts of change and innovation. In the context of this study, TTOs carry out different tasks related to the management of technology transfer. However, resources are unevenly allocated across TTOs and, consequently, TTOs' performance is also heterogeneous across universities. Different patterns are observed based on the relative importance given to the different components of TTOs' objective function in which technology transfer is critical. In this setting, the performance aspirations of publicly funded TTOs are more linked to the deepening of their technology transfer outputs and the rapid commercialization of their innovations, rather than economic results derived from short-term projects.

Building on performance-feedback models (Levinthal and March 1981; Chen and Miller 2007), it seems plausible to argue that TTOs cater to the tastes of industry by fueling the market with value-adding innovations, and that performance evaluations can play a decisive role in shaping TTOs' strategic paths (Labianca et al. 2009). Benchmarking analyses-i.e., based on both the organization's own historical record and the organization's reference group-indicate whether the organization is performing poorly (below its aspiration level) or better than expected (above its aspiration level).

Regardless the reference group, performance below the aspiration level raises serious questions about the legitimacy of organizational practices and creates the need to alter current activities (Levitt and March 1988; Greve 1998). TTOs are not the exception. TTOs operate in a 
competitive environment - the market for knowledge innovations — which increases the incentives of managers for using performance feedback as an adaptive behavior mechanism. Organizational change is a costly process; however, the presence of more specialized staff - that is instrumental to support knowledge transfer tasks - can contribute to a smooth transition during the adaptation period that follows the implementation of new strategies (Macho-Stadler et al. 2007). Therefore, the depth of the change in the configuration of the TTOs' output portfolio may likely be determined by the degree of specialization of TTO's resources.

Poor performance stimulates the vigorous search for new ways to enhance internal practices that contribute to move the TTO's performance closer to its aspiration level (Baum and Dahlin 2007). In the context of this study, the objective function of publicly funded TTOs describes the maximization of technology transfer outputs. Therefore, we argue that TTOs whose performance is below their aspiration level will modify their organizational practices and strategic choices, and that these changes will materialize in changes in the configuration of the TTOs' technology transfer outcomes.

On contrary, can we expect that high-performing TTOs fall into complacency or inefficient inertia? Note that the markets of knowledge and innovations are dynamic and highly competitive and that TTOs compete for attracting the attention of industries seeking to fund and commercialize their innovations. Also, TTOs whose performance is above their aspiration levels will likely enjoy a more solid organizational and financial position to engage in continuous change practices which makes it difficult for other TTOs to catch-up. This argument is at the heart of competitive advantage theories that emphasize that innovativeness often provides the potential for the effective development of new products and services, significant changes in the organization's routines and practices, as well as changes in their strategies to compete in the market (Baum and Dahlin 2007; Labianca et al. 2009). Thus, according to this competitive advantage view, TTOs whose performance is above their aspiration levels will attempt to stay ahead of competitors by continuously diversifying their technology transfer activities as a way to consolidate their market position (Chen and Miller 2007; Iyer and Miller 2008). Additionally, change is a desired policy among successful TTOs - in terms of aspiration performancebecause their mangers will have access to additional resources and abilities to pursue new strategic choices linked to the configuration of the TTO's portfolio (Levinthal and March 1981).

Although in some contexts competitors' actions might remain hidden, it should be kept in mind that Spanish TTOs must report their activity to the Network of Spanish Technology Transfer Offices (RedOTRI). Thus, the experience and technology transfer outcomes of TTOs are visible, interpretable based on available information, and generalizable across TTOs. Also, because TTOs employ the same basic resources (specialized staff, infrastructures and networks) decision makers can gain access to valuable experience created by other publicly funded TTOs. 
The core of our analysis is to scrutinize the effects on TTOs' productivity of aspirationperformance feedback. Taken together, these arguments and evidence suggest that TTOs whose performance is below their-own and market aspiration levels will engage in drastic change-in terms of their technology transfer portfolio - seeking to improve their performance, while TTOs with an above-aspiration performance will intensify and diversify their technology transfer activities to consolidate their competitive position.

\section{Research context: Technology transfer in Spanish public universities}

In Spain, the higher education system has gone through significant changes during the past decades. Before 2001, the Organic Law of Universities (LRU) 11/1983 was the legal framework regulating the hiring and contracting of university professors and researchers. This law grouped faculty in two main categories: permanent faculty (civil servants) and fixed-term faculty (non-civil servants). In 2001 a profound reform took place, and with the new Universities Act (LOU, 6/2001) in force universities enjoyed greater autonomy to restructure the processes through which academics are hired. Following the enactment of the 2001 Universities Act, the Spanish Government created in 2002 the Agency for Quality Assessment and Accreditation Trust (ANECA). This agency is the main authority within the higher education system, which evaluates and endorses the scientific activity of university researchers in Spain. The highly decentralized structure of Spain's institutions facilitated the creation of similar agencies with the same attributions in some regions (e.g., Catalonia and Galicia).

With the new regulatory frame governing universities in place, universities' research orientation is further emphasized, and the parameterization of technology transfer outputs facilitates the evaluation of both universities and academics (Berbegal-Mirabent et al. 2013; Lafuente and Berbegal-Mirabent 2017). The primary objective of this evaluation process is to ensure that candidates for academic positions have an appropriate level of academic merit. The weight assigned to the various components of a $\mathrm{CV}$ (i.e. teaching experience, research experience, educational background, and work experience) varies according to the teaching body (there are several categories), academic discipline and academic position. The higher the position, the more important are one's research credentials (i.e. publication history, research projects, technology transfer). Research experience typically accounts for at least half of the total score. Particularly, the number of papers published in academic journals is the most important criterion valued to accredit professors. Specifically, the weight of scientific publications in the final evaluation ranges between 26\% and 35\% (according to the knowledge filed). On the contrary, technology transfer outputs such as patents or spin-offs have a low impact, representing between $3 \%$ and $12 \%$ of the total evaluation score.

These imbalances on the weights assigned to basic and applied research outputs suggest that researchers' motivation to engage in the different types of technology transfer activities 
might differ based on their contractual situation. For young academics and professors in a weaker contractual position, their academic career will be greatly determined by their capacity to publish their research. They have strong incentives to publish in order to create reputational signals that will likely increase their probability of being internally promoted (Lafuente and Berbegal-Mirabent 2017). To the contrary, full professors have no exogenous incentives to publish, and their only motivation is endogenously determined by their own interest in conducting research in their knowledge fields. Research conducted by full professors may be motivated by knowledge and technology transfer dissemination objectives, the enhancement or consolidation of research projects, or by reputational factors (Siegel et al. 2007).

In Spain TTOs are the units responsible for the management and transfer of technology transfer outputs (Caldera and Debande 2010; Guerrero and Urbano 2012). All Spanish public universities have an affiliated TTO whose specialized staff provides different services, including the quality evaluation of the inventions disclosed by researchers, support for patent application, negotiation of licensing contracts, and support for researchers in the creation of spin-offs.

Concerning the technology transfer intensity of Spanish public universities, data from the Spanish Statistical Office (INE: www.ine.es) indicate that universities invested 3.6 billion euro on R\&D in 2014, of which 39\% (1.4 billion euro) came from market sources. Note that the universities' R\&D budget represents $35 \%$ of their total budget (10.3 billion euro) in the same year. Also, figures show that the relevance of TTOs within the university system has grown. Information obtained from the Network of Spanish Technology Transfer Offices (RedOTRI: www.redotriuniversidades.net) reveals that $50 \%$ of the TTOs' budget came from the universities in 2011, while in 2014 this percentage stood at 58\%. Private resources represented $22 \%$ of the TTOs budget in 2011, half of which was generated by university-industry collaboration projects. In 2014, university-industry collaboration projects represented 55\% of the TTO's budget line referring to private funding which grew to $29 \%$ of the total TTOs' budget.

\section{Data and methods}

\subsection{Data}

The data used in this study come from two sources of information. First, we employ the reports provided by the Spanish Association of University Rectors (Conferencia de Rectores de Universidades Españolas, CRUE). The CRUE databases contain data on the faculty working in Spanish public universities. Second, all variables related to knowledge-transfer resources and outcomes were collected from the annual reports available from the Network of Spanish Technology Transfer Offices (RedOTRI). More concretely, from the RedOTRI reports we obtained detailed organizational data on the configuration of the workforce among the sampled technology transfer offices, distinguishing between staff specialized in knowledge-transfer areas (business start-up process, design of licensing contracts, and intellectual property rights) and 
administrative support staff. Additionally, this database provides information on the number of spin-offs, licenses and patents generated by the study TTOs.

The database comprises information for all TTOs affiliated to Spanish public universities from 2006 to 2011 (47 organizations). Yet, in the interest of following a rigorous methodology, three TTOs were excluded from the sample due to lack of reliable information on employees and technology transfer outputs (Universidad de Las Palmas, Universidad de León, Universidad Politécnica de Cartagena). Therefore, the final sample consists of 44 TTOs for the period 2006-2011 (264 observations).

\subsection{Efficiency analysis}

When dealing with multiple inputs yielding multiple outputs, efficiency literature often makes use of data envelopment analysis (DEA) frontier methods (see, e.g., Cooper et al. 2011; Grifell-Tatjé and Lovell 2015). DEA is a non-parametric technique that, through linear programming, approximates the true but unknown technology without imposing any restriction on the sample distribution. The primary technological assumption of DEA models is that production units (in our case, universities) $(i)$ use a set of $\mathbf{x}=\left(x_{1}, \ldots x_{J}\right) \in R_{+}^{J}$ inputs to produce a set of $\mathbf{y}=\left(y_{1}, \ldots, y_{M}\right) \in R_{+}^{M}$ outputs, and that these sets form the technology in the sector $(T)$ : $T=\{(\mathbf{x}, \mathbf{y}, t): \mathbf{x}$ can produce $\mathbf{y}$ at time $t\}$. DEA is a complex benchmarking technique that yields a production possibilities set where efficient decision-making units positioned on this surface shape the frontier. For the rest of units DEA computes an inefficiency score indicating the units' distance to the best practice frontier.

The technology in DEA models has two properties that are worth defining. First, in this study the technology exhibits variable returns to scale (VRS) because pure technical efficiency measures (VRS) capture outcomes linked to practices undergone by decision makers in the short term (Chambers and Pope 1996). The second assumption deals with the measurement orientation (input minimization or output maximization). The proposed DEA model maintains an output orientation. Business managers are often given output targets and told to produce them most efficiently, that is, with minimum inputs (Sengupta 1987, p. 2290). On contrary, in the public sector the workforce and assets tend to be fixed and policy-makers seek to produce the maximal possible output given the resources available (Berbegal-Mirabent et al. 2013). The following linear program models the described technology and computes, for each TTO $(i)$ and each period $(t)$, the efficiency score via an output distance function $\left(D_{i}^{t}\left(x_{i}^{t}, y_{i}^{t}\right)\right)$ : 


$$
\begin{array}{lll}
D_{i}^{t}\left(x_{i}^{t}, y_{i}^{t}\right) & =\max \theta_{i} \\
\text { subject to } & \sum_{i=1}^{N} \lambda_{i}^{t} y_{i, m}^{t} \geq \theta_{i} y_{i, m}^{t} & m=1, \ldots, M \\
& \sum_{i=1}^{N} \lambda_{i}^{t} x_{i, j}^{t} \leq x_{i, j}^{t} & j=1, \ldots, J \\
& \sum_{i=1}^{N} \lambda_{i}^{t}=1, \quad \lambda_{i}^{t}>0 & i=1, \ldots, N
\end{array}
$$

The drawn technology in equation (1) describes how TTOs transform their available resources (x: faculty, TTO staff specialized in technology-transfer activities, and TTO administrative support staff) ${ }^{2}$ into the maximum possible output (y: spin-offs, licenses, and patents), uses $\lambda$ as intensity weights to form the linear combinations of the sampled universities $(N)$, and introduces the restriction $\sum_{i=1}^{N} \lambda_{i}^{t}=1$ to impose variable returns to scale to the technology. The term $\theta$ is the efficiency score, and for efficient universities $\theta=1$. For inefficient universities $\theta>1$ and $1-\theta$ points to the degree of inefficiency.

Next, the distance functions can be used to compute changes in total factor productivity (TFP) between two periods through the Malmquist index $(M(\cdot))$. The Malmquist TFP index were first introduced by Malmquist (1953) and has further been developed in the nonparametric framework by, among others, Caves et al. (1982), Färe and Grosskopf (1989) and Grifell-Tatjé and Lovell (1999). In a multiple input-output setting, this index reflects changes (progress or regress) in productivity along with changes (progress or regress) of the frontier technology over time.

In this study, the output-oriented Malmquist TFP index $\left(M_{i}\left(x_{t}, y_{t}, x_{t+1}, y_{t+1}\right)\right)$ is computed for each TTO $(i)$ on the benchmark technologies in period $t$ and $t+1$ as follows:

$$
\begin{aligned}
& M_{i}\left(x_{t}, y_{t}, x_{t+1}, y_{t+1}\right)=\left[\frac{D_{i}^{t+1}\left(x^{t+1}, y^{t+1}\right)}{D_{i}^{t}\left(x^{t}, y^{t}\right)}\right] \times\left[\frac{D_{i}^{t}\left(x^{t+1}, y^{t+1}\right)}{D_{i}^{t+1}\left(x^{t+1}, y^{t+1}\right)} \times \frac{D_{i}^{t}\left(x^{t}, y^{t}\right)}{D_{i}^{t+1}\left(x^{t}, y^{t}\right)}\right]^{0.50} \\
& M_{i}\left(x_{t}, y_{t}, x_{t+1}, y_{t+1}\right)=\Delta T E \times \Delta T C
\end{aligned}
$$

The estimated TFP index distinguishes between the catch-up effect or the operating efficiency change $(\triangle T E)$ - variations in technical efficiency between periods $t$ and $t+1$ - and the effect of technical change $(\Delta T C)$, that is, the shift in technology between the two periods (the geometric product of ratios inside the square brackets). Values greater than unity indicate productivity growth (progress), while values lower than one point to decline (regress) between periods $t$ and $t+1$. Analogous interpretations hold for the components of the TFP index.

As we indicated above, TTOs' productivity paths are evaluated under the premise that they capitalize on their specific resources (faculty, TTO staff specialized in technology-transfer

\footnotetext{
${ }^{2}$ It should be kept in mind that, during the analyzed period, reliable data on the TTO's budget are not available from the RedOTRI annual reports for 12 universities.
} 
activities, and TTO administrative support staff) to produce technology-transfer outcomes (spinoffs, licenses, and patents). Note that the selected input-output set matches the theory presented in section 2 and is in line with prior work dealing with the performance of TTOs. TTOs are intermediaries between suppliers of innovations (university scientists) and those who can potentially commercialize the generated knowledge (businesses, entrepreneurs, venture capitalists) (Siegel et al. 2007, p. 641). Thus, faculty is a good proxy for the stock of available human capital with the capacity to create knowledge with commercial potential. A successful technology transfer process heavily relies on the management of intellectual property by TTOs' employees (Macho-Stadler et al. 2007). TTOs with more specialized staff arguably have a greater capacity to evaluate and commercialize the knowledge generated by researchers (Thursby and Kemp 2002), while administrative staff assists the specialized staff in the day-today activities related to the different technology transfer tasks (Caldera and Debande 2010).

Concerning the TTOs' output set, existing research widely supports that TTOs are knowledge brokers whose primary objective is the commercialization of knowledge via patents, licenses, and university-based spin-offs (Thursby and Kemp 2002; Chappel et al. 2005; Siegel et al. 2007; Caldera and Debande 2010; Algieri et al., 2013; Berbegal-Mirabent et al. 2013)

Tables 1 and 2 present the descriptive statistics for the input-output set. Note that in our sample some TTOs report zero data values in the output set. More concretely, during the analyzed period nine TTOs report zero spin-offs, while five and two TTOs did not create any license or patent, respectively. Much has been said about how to handle 'badly behaved data' in DEA models (see, e.g., Thanassoulis et al. 2008). In fact, zero output values present no computational problems in DEA models and the estimated efficiency scores are technically feasible (Podinovski and Thanassoulis 2007, p. 119). From an economic perspective, zero output values only point to the ineffective consumption of resources by a focal unit which translates into the production of zero outputs. ${ }^{3}$ Also, it is worth mentioning that in our dataset the output vector $(\mathbf{y})$ for all TTOs is positive $(\mathbf{y}>0)$ in all periods. Although some TTOs report zero values in some outputs, all TTOs in the sample report the production of at least one technology transfer output during the analyzed period (2006-2011).

----- Insert Tables 1 and 2 about here -----

\subsection{Second stage analysis: Aspiration-performance feedback and portfolio configuration}

The second stage analysis evaluates the relationship between productivity and aspiration performance among TTOs affiliated to public universities. To this end, note that we employ

\footnotetext{
${ }^{3}$ Although it is not the case in our data, we extend the analysis to the case of zero values in the input set. Zero input values are problematic in DEA models. From an economic point of view, zero input values indicate that the focal unit can produce outputs without consuming resources, which leads to unfeasible DEA scores (see Thanassoulis et al. (2008) for a comprehensive review on this issue).
} 
vector algebra to operationalize the portfolio of technology transfer outcomes. The complexity of the TTO's portfolio increases with the number of products in a given category (spin-offs, licenses and patents). Based on vector algebra, we undertook a pairwise comparison by calculating cosine values between the vectors of two TTOs $\left(f_{i}, f_{k}\right)$ across all technology transfer outcomes $(\mathbf{y})$ in the sector at period $t$.

Configuration of TTO portfolio $=\frac{\vec{f}_{i}, \vec{f}_{k}}{|\vec{f}| \times\left|\vec{f}_{k}\right|}=\frac{\sum_{i=1}^{N} \mathbf{y}_{i} \times \mathbf{y}_{k}}{\sqrt{\sum_{i=1}^{N} \mathbf{y}_{i}^{2}} \times \sqrt{\sum_{i=1}^{N} \mathbf{y}_{k}^{2}}}$

In equation (3), the vector of the number of products in each category $(\mathbf{y})$ for each TTO $\left(f_{i}\right)$ was compared to the vector of values of the rest of TTOs $\left(f_{k}\right)$ in the same category. As the angle between the vectors shortens, the cosine value approaches 1 indicating that the vector of technology transfer outputs produced by the two TTOs is more similar.

For example, let's consider the case of a fictitious $\operatorname{TTO}\left(f_{i}\right)$ whose vector of outputs is $[0,1,2]$, that is, the focal TTO does not produce any output in the first category (spin-offs), produces one output in the second category (licenses) and produces two outputs in the third category (patents). Similarly, for a reference $\operatorname{TTO}\left(f_{k=1}\right)$, the vector of outputs is $[1,2,3]$. Following equation (3), the cosine value for the comparison of the two TTOs is computed as $\frac{8}{\sqrt{0+1+4} \times \sqrt{1+4+9}}=0.96$. Now suppose a second reference TTO with a similar number of outputs but with a different configuration $[3,2,1]$. In this case, the cosine value between the focal TTO $\left(f_{i}\right)$ and the reference $\operatorname{TTO}\left(f_{k=2}\right)$ is $\frac{4}{\sqrt{0+1+4} \times \sqrt{9+4+1}}=0.48$. Although the reference TTOs $\left(f_{k=1}, f_{k=2}\right)$ have the same total number of outputs, the configuration of the output portfolio - based on the relative weight of each category in the output mix — of the focal $\operatorname{TTO}\left(f_{i}\right)$ is more similar to $f_{k=1}$ than $f_{k=2}$.

Therefore, the proposed measure of portfolio configuration allows at differentiating three dimensions of TTO outputs: length (total output), breadth (categories), and depth (relevance of categories in the output mix based on the quantity of output in each category). In line with the arguments presented in section 2.2, this variable permits us to assess the extent to which TTOs benchmark their-own' and other TTOs' performance and how productivity is affected by strategic actions resulting from the analysis of TTOs' aspiration performance levels.

For each period, we measure the TTO-specific aspiration performance $\left(\mathrm{AP}^{\mathrm{TTO}}\right)$ as the value of the configuration of the TTO portfolio minus its-own average value for the period prior the focal year of analysis. To allow for different slopes above and below aspiration levels, we split $\mathrm{AP}^{\mathrm{TTO}}$ into two variables: 1) $\mathrm{AP}^{\mathrm{TTO}}>0$ equals to zero for TTOs where performance is 
below their-own performance aspirations, and equals $\mathrm{AP}^{\mathrm{TTO}}$ otherwise; 2) $\mathrm{AP}^{\mathrm{TTO}}<0$ is zero for TTOs where performance is above their aspirations, and equals $\mathrm{AP}^{\mathrm{TTO}}$ otherwise.

Likewise, for each TTO we defined the market aspiration level $\left(\mathrm{AP}^{\mathrm{MKT}}\right)$ as the value of the configuration of the TTO portfolio minus the performance of other TTOs, that is, the average value of the configuration of the TTO portfolio for each period. Again, to permit different slopes for values above and below the aspiration level, we split $\mathrm{AP}^{\mathrm{MKT}}$ into two variables: 1) $\mathrm{AP}^{\mathrm{MKT}}>0$ equals to $\mathrm{AP}^{\mathrm{MKT}}$ for TTOs where performance is above market aspirations (and zero otherwise); 2) $\mathrm{AP}^{\mathrm{MKT}}<0$ is zero for TTOs where performance is above market aspirations, and equals $\mathrm{AP}^{\mathrm{MKT}}$ otherwise.

Additionally, we introduce a set of control variables commonly found in studies dealing with technology transfer performance (Friedman and Silberman 2003; Wright et al. 2007; Ambos et al. 2008; Agasisti and Wolszczak-Derlacz 2015; Vinig and Lips 2015). University size is measured by the total faculty, while university age is introduced as a proxy of market experience. The size and experience of the TTO is measured as the total staff and age, respectively. For both universities and TTOs, note that the variables related to size and experience are logged to reduce skewness. To account for the potential benefits derived from the presence of technology transfer intermediate organizations, we introduced a dummy variable taking the value of one if the university has a science parks, and zero otherwise. A dummy variable taking the value of one for polytechnic universities takes into account the potentially greater marketability of engineering-based inventions, compared to inventions from other disciplines. Time dummy variables are introduced to control for time trends (in all models 2011 is the base year). Finally, and similar to prior work (Chappel et al. 2005; Siegel et al., 2007), we include a set of regional dummies to rule out the potential effects of economic and other environmental conditions that may affect TTOs' productivity (in all models Madrid is the omitted category). Descriptive statistics for the study variables are presented in Table 3.

----- Insert Table 3 about here -----

We employ panel data techniques to estimate the proposed model which emphasizes a relationship between aspiration performance and universities' technology transfer productivity. Pooling repeated observations on the same organizations violate the assumption of independence of observations, resulting in autocorrelation in the residuals. First-order autocorrelation occurs when the disturbances in one time period are correlated with those in the previous time period, resulting in incorrect variance estimates, rendering ordinary least squares (OLS) estimates inefficient and biased (Wooldridge 2002). Therefore, we estimate randomeffects (GLS) panel data models with robust standard errors to correct for autocorrelation of error terms due to constant university-specific effects (Greene 2003). Additionally, the proposed 
estimation approach allows at evaluating the effect of relevant time-invariant factors on technology transfer productivity. To evaluate the role of aspiration performance empirically we propose a random-effects model with the following form:

$$
\begin{aligned}
\mathrm{TFP}_{i t} & =\beta_{0}+\beta_{1} \mathrm{AP}_{i t}^{T T O}<0+\beta_{2} \mathrm{AP}_{i t}^{T T O}>0+\beta_{3} \mathrm{AP}_{i t}^{M K T}<0+\beta_{4} \mathrm{AP}_{i t}^{M K T}>0 \\
& +\beta_{5} \text { Control variables } i t \\
& +\beta_{6} T_{t}+\varepsilon_{i t}
\end{aligned}
$$

In equation (4) TFP is the Malmquist TFP index computed from equation (2), $\beta_{j}$ are parameter estimates estimated for the independent variables $(j), \varepsilon$ is the normally distributed error term that varies cross-universities and cross-time $(t)$, while $T$ refers to the set of time dummy variables.

We estimated the Hausman (1978) specification test to further validate the appropriateness of the proposed regression models. Results for model 1 (Hausman test: 4.97 and $p$-value $<0.89$ ) and model 2 (Hausman test: 6.95 and $p$-value $<0.86$ ) indicate that random effects estimations are independent of university-specific effects-i.e., regressors are consistent - thus confirming that random-effects coefficients are consistent and efficient (Wooldridge 2002).

\section{Results}

\subsection{Productivity assessment of Spanish Technology Transfer Offices (TTOs)}

This section presents the results of the efficiency analysis. Table 4 shows the summary statistics of the Malmquist TFP results, while Appendix 1 presents the productivity results for the analyzed Spanish publicly funded TTOs. Overall, the findings in Table 4 and Figure 1 reveal that, on average, the analyzed TTOs improved their productivity level by $4 \%$, and that technology transfer productivity declined after 2009 to the level of $1.73 \%$ in the period 2010 2011.

----- Insert Table 4 about here -----

Additionally, Figure 2 shows the results for the components of the Malmquist TFP index. The dotted line in the figure shows the operating efficiency change, which is linked to the catching-up effect and is computed for each university as the difference in the distance to the efficiency frontier between period $t$ and $t+1$. The technical change (continuous line in Figure 2) captures the shift in the frontier between period $t$ and $t+1$, thus unveiling the progress or regress of the analyzed TTOs with similar input-output configurations. Results in the figure show that technology transfer productivity is mainly driven by positive shifts in the efficiency frontier (on average $2.54 \%$ ), with the exception of the period 2007-2008 where the technology transfer frontier regressed by $3.58 \%$. 
Consistent with the period of economic downturn that characterized Spain's economy, Spanish public TTOs show a fall in operating efficiency after 2009, that is, their distance to the technology transfer frontier has increased (deteriorated) between period $t$ and $t+1$ as a result of the ineffective utilization of resources in the production of technology-transfer outcomes.

----- Insert Figures 1 and 2 about here -----

A closer look at the results reveals that the number of efficient universities placed on the technology transfer frontier varies between 13 (2009) and seven (2011). We also note that five TTOs affiliated to public universities consistently shape the technology transfer frontier, that is, they are efficient in four or five periods: Universidad of Sevilla, University of Salamanca, Polytechnic University of Catalonia, Polytechnic University of Valencia, and Polytechnic University of Madrid.

These TTOs are benchmark targets for inefficient TTOs, and they show a greater average level of technology transfer outputs, compared to inefficient institutions: 4.63 spin-offs (inefficient universities: 2.14 spin-offs), 9.83 licenses (inefficient universities: 3.30 licenses), and 13.74 patents (inefficient universities: 5.71 patents). For each technology transfer output, the comparison of the average values between efficient and inefficient TTOs is statistically significant at $1 \%$ level (Kruskal-Wallis test).

Finally we note that efficient TTOs affiliated to polytechnic institutions report the highest level of technology transfer outputs (spin-offs: 7.46, licenses: 15.80, and patents: 22.80). This result is in line with prior research emphasizing the superior technology transfer orientation of TTOs working in universities with close ties to the industry, such as polytechnics and institutions with engineering schools (see e.g., Siegel et al. 2003; Anderson et al. 2007; Caldera and Debande 2010; Perkerman et al. 2013).

\subsection{Second stage analysis: Aspiration performance and technology transfer productivity}

Table 5 reports the estimates of the random-effects regression models linking aspiration performance and technology transfer productivity. Model 1 is the baseline specification which includes the aspiration performance levels and the control variables. Model 2 includes the main effects of aspiration performance based on both TTO-specific and market levels.

To address the threat of collinearity, we computed the average variance inflation factor (VIF) for all variables. The average VIF value for model 12.66 and ranges between 1.32 and 6.89, while for model 2 the average VIF is 2.77 (ranging between 1.33 and 7.91). Note that all the VIF values do not exceed 10 - a generally accepted rule of thumb for assessing collinearity. The results for this diagnostic test do not raise collinearity concerns. 
To aid in the interpretation of the results, we plot the aspiration performance variables based on estimates from model 2 (equation (4)). The results are presented in Figure 3. The vertical axis indicates the estimated technology transfer productivity, and the horizontal axis indicates the aspiration performance levels. Control variables are set at their sample means.

----- Insert Figure 3 about here -----

Concerning the key results of the analysis, from model 1 in Table 5 we note that the coefficient for own aspiration performance is positive and statistically significant $\left(\mathrm{AP}^{\mathrm{TTO}}=\right.$ 0.0164 and $p$-value $<1 \%$ ). This result indicates that TTOs whose technology transfer portfolio is above their own aspiration performance level show higher levels of technology transfer productivity. Therefore, increased complexity in the TTO's technology transfer portfolio enhances productivity. The pattern of own aspiration performance in model 2 of Table 5 suggests that technology transfer productivity increases for TTOs that increase the complexity of their technology transfer portfolio. One possible explanation for this result is that TTOs benchmark their own aspiration level to introduce changes in their technology transfer portfolio, irrespective of whether the TTO's portfolio is below or above their own aspiration level. This result is in line with the competitive advantage view of organizational change that underlines the role of change based on own aspiration levels to consolidate market positioning (Iyer and Miller 2008). This indicates that TTOs benchmark the outcomes of their own portfolio, and that increased diversification in the TTOs' portfolio with respect to their own aspiration level yields superior productivity results.

Figure 3 graphically illustrates that the relationship between aspiration performance and productivity is steeper below the TTO's performance aspirations. That is, the relative slope and magnitude of the effect of performance below aspirations $\left(\beta_{1}=0.0278\right.$ and $p-$ value $\left.<1 \%\right)$ is greater than that estimated for performance above own aspiration level $\left(\beta_{1}=0.0126\right.$ and $p-$ value $\left.<10 \%\right)$. This finding indicates that productivity improvements that follow changes in the configuration of the technology transfer portfolio are greater when performance is below the TTOs' own aspirations. Managers tend to react more strongly to threats than to opportunities (Kahneman and Tversky 1979), and performance below aspirations stimulates the search of new ways of doing things (Greve 1998). Thus, this result suggests that managers of TTOs whose performance is far from their own aspirations are more open to promote changes in resource allocation practices and, consequently, in the configuration of their technology transfer portfolio with the objective to raise productivity closer to their aspirations. 
In contrast, TTO actively engaging in technology transfer activities above market aspiration show a significant deterioration in their technology transfer productivity (model 2 in Table 5: $\beta_{1}=-0.0103$ and $p-$ value $<5 \%$ ). Following the decomposition of the Malmquist index presented in equation (2), this result may well originate from variations in operating efficiency $(T E)$ or from shifts in the technology $(T C)$. Variations in the operating efficiency component $(T E)$ are linked to the exploitation of available resources as it indicates if the focal TTO is moving closer or farther away from the efficiency frontier (catch-up effect); while technical change $(T C)$ measures the shift in the technology frontier resulting from decisionmaking processes - in terms of resource exploitation and output production - and from the introduction of cutting-edge technologies (Grifell-Tatjé and Lovell 1999). Thus, by analyzing the components of the Malmquist index we can test whether the negative effect on productivity of portfolio's complexity above market aspirations comes from an inefficient use of resources (variations in $T E$ ), or from factors linked to technical change (TC) that can be related to organizational inertia, such as the ineffective introduction of new technologies and the development of strategies or policy-driven actions associated with the greater (or lower) exploitation or specific resources. ${ }^{4}$

Looking at the results we note that the productivity level of TTOs whose portfolio's configuration is below market aspirations (Malmquist index: 1.09) is significantly higher than that reported for TTOs whose portfolio's complexity is above market aspirations (Malmquist index: 0.96) (Kruskal-Wallis test: 11.30, $p$-value $<0.001$ ). An examination of the productivity components reveals that this gap is caused by significant differences in operating efficiency $(T E)$ (Kruskal-Wallis test: $4.75, p$-value $=0.028)$ : TTOs whose portfolio's complexity is below market aspirations $=1.05$, TTOs whose portfolio's complexity is above market aspirations $=$ 0.95. The comparison of the technical change (TC) component between the two groups yields a not significant result (Kruskal-Wallis test: $2.33, p$-value $=0.127$ ).

Instead of organizational inertia (Iyer and Miller, 2008), these findings indicate that greater diversification of TTOs' portfolio may increase the complexity of the operational tasks necessary to generate technology transfer outcomes, which causes the reported falls in the productivity level of TTOs whose portfolio reports a complexity level above market aspirations.

\section{Discussion}

At the organizational level, change is difficult but necessary. Nevertheless, organizational change entails inherent risks (Labianca et al. 2009). Therefore, the analysis of the

\footnotetext{
${ }^{4}$ Literature on the definition and causes of technical change is extensive. In this study, technical change refers to shifts of the production function in the input-output space that originate from different combinations in the input-mix and the output-mix. In the context of non-parametric productivity models, a more in-depth analysis of technical change can be found in Kumar and Russell (2002) and Grifell-Tatjé and Lovell (2015).
} 
processes underlying organizational change is critical to understand the trade-offs between resource allocation policies and the subsequent change in organizational performance. Our result that changes in the TTOs' portfolio based on the benchmarking of other TTOs may cause unintended negative effects on productivity confirms this argument. We argue that this result may reflect that changes in the TTOs' technology transfer portfolio modify operational tasks and the way the TTOs exploit their resources.

Prior work often assumes that organizations benchmark their market peers to form their performance aspiration levels, thus ignoring the possibility that organizations mirror to themselves when it comes to create their performance aspirations (Chen and Miller 2007). We show that, among TTOs, enhanced productivity follows organizational change based on the TTOs' own historical performance. The findings are in line with studies emphasizing that superior performance is not exclusively linked to the use of market peers or industry average values as reference points (Baum and Dahlin 2007; Labianca et al. 2009). This result indicates that, in their search for non-local information, TTO managers might be constrained by focusing on a limited number of potentially similar TTOs and strategic factors. By benchmarking heterogeneous TTOs - in terms of both available resources and the configuration of their technology-transfer portfolio-managers may adopt strategic actions that are not compatible with the configuration of their resources, which translate into ineffective changes in the TTOs' operations and, consequently, poor productivity results.

On contrary, the positive effects on TFP of changes in the TTOs' portfolio based on internal information may well reflect an effective resource exploitation policy. TTOs have strong incentives to modify the configuration of their technology-transfer portfolio, irrespective of whether their performance is above or below their own aspiration level. By benchmarking their own historical record, TTOs generate changes more aligned with the configuration of their input-output set, thus incurring in lower adaptation costs. For example, internal actions that may strengthen the TTO's productivity include the support of team work dynamics among employees, as well as the introduction of both training programs and continuous improvement processes that emphasize learning. These actions may constitute a source of competitive advantage (Baum and Dahlin 2007). Also, the exploitation of these factors signals the extent to which TTOs strive for superior performance apart from external comparisons.

\section{Concluding remarks, implications and directions for future research}

In this study, we propose that TTOs' technology transfer productivity is a function of scientists' human capital and TTO's specific resources. Furthermore, we argue that the role of TTOs as driving force of change, along with differences in the configuration of the TTO's output portfolio, have implications for the productivity of TTOs affiliated to public universities. Our approach offers a compelling vision of how TTOs seek to enhance their productivity levels 
through strategic actions linked to changes in the configuration of their technology transfer portfolio. Overall, results suggest that the productivity of Spanish publicly funded TTOs improved, on average, 4\% between 2006 and 2011 and that, coinciding with the economic slowdown in Spain, technology transfer productivity declined between 2009 and 2011.

The findings of this study have relevant academic and policy implications. As any organization, TTOs engage in different performance-enhancing strategic actions. However, we find that the maximization of all types of technology transfer outputs should not necessarily be the objective of TTOs affiliated to public universities. These results fuel the academic debate on both the multidimensionality of TTOs' objective function (Siegel et al. 2007; Vinig and Lips 2015) and the need to match TTOs' objectives with those of the different stakeholders that take part of technology transfer processes (Kim 2013; Fitzgerald and Cunningham 2016). Our results have also implications for the closely related literature on performance feedback models (Greve 1998; Baum and Dahlin 2007; Labianca et al. 2009). By linking benchmarking to TTOs' strategic choices that materialize in changes in the configuration of TTOs' output portfolio, our analysis shows that benchmarking own and other peers have different impacts on productivity.

By definition, TTOs are catalysts of change and innovation, and the successful commercialization of inventions requires specific investments, in the case of TTOs the creation of efficient organizational structures and the recruiting of highly skilled staff who support the transfer of new knowledge to the industry. Our results suggesting that enhanced productivity follows organizational change based on the evaluation of the TTOs' own historical record contribute to better understand how performance feedback impacts TTOs' strategy making and, consequently, subsequent productivity.

We suggest that policy makers and TTO managers need to turn their attention to the characteristics of the TTO's operational processes when considering the introduction of strategic changes that will modify the TTO's technology transfer portfolio. Drastic changes in the configuration of the technology transfer portfolio as a result of the benchmarking of own and market aspiration levels have different effects on productivity. The analysis of the productivity patterns of TTOs reveals that benchmark own performance might promote efficient changes of TTOs' output portfolio, thus leading to superior TFP levels. On contrary, benchmarking market peers - other TTOs - might prove itself ineffective to enhance technology transfer productivity. Therefore, the prioritization of changes in the technology transfer portfolio based on the market aspiration levels may increase operational costs, which is detrimental to both learning and productivity (Chen and Miller 2007; Iyer and Miller 2008). Additionally, our results underline the relevance of internal analyses. By conducting a profound analysis of available resources TTO managers will be in a better position both for understanding the potential value of benchmarking different targets (internal or external) and for determining the strategy making of TTOs. 
It must, however, be mentioned a series of limitations to the present study that, in turn, represent avenues for future research. First, like other studies on productivity (see, e.g., Berbegal-Mirabent et al. 2013; Agasisti and Wolszczak-Derlacz 2015), the data do not permit the direct analysis of the underlying technology transfer process. We present various interpretations of how productivity is conditioned by TTOs' practices; however, we do not evaluate how productivity varies at different stages of the knowledge generation process, nor do we assess the processes through which scientists generate-individually or collectively-new knowledge and channel it to the TTO. Further research on this issue would be valuable. For example, future studies should evaluate the researchers' response to incentives created by TTOs, and determine both the conditions under which academics engage in technology transfer activities and how the TTOs' operations affect these processes. Second, the analyzed period definitely influences our productivity estimates. Publicly funded TTOs were severely damaged by the budget cuts that followed the economic downturn that affects Spain after 2008. In this sense, future research should evaluate our argument on the differentiated impact on TTOs' productivity of different benchmarking strategies using more updated data. Finally, cultural contexts, different regulatory frameworks, and variations in the flexibility and development of technology transfer activities affect the TTOs' policies and their productivity. The geographic specificity of the study calls for obvious caution when interpreting and generalizing its findings.

\section{References}

Agasisti, T., Wolszczak-Derlacz, J. (2015). Exploring efficiency differentials between Italian and Polish universities, 2001-11. Science and Public Policy, 43(1), 128-142.

Algieri, B., Aquino, A., Succurro, M. (2013). Technology transfer offices and academic spin-off creation: the case of Italy. Journal of Technology Transfer, 38(4), 382-400.

Ambos, T.C., Mäkelä, K., Birkinshaw, J., D’Este, P. (2008). When does university research get commercialized? Creating ambidexterity in research institutions. Journal of Management Studies, 45(8), 1424-1447.

Anderson, T.R., Daim, T.U., Lavoie, F.F. (2007). Measuring the efficiency of university technology transfer. Technovation, 27(5), 306-318.

Baldini, N. (2009). Implementing Bayh-Dole-like laws: Faculty problems and their impact on university patenting activity. Research Policy, 38(8), 1217-1224.

Balsmeier, B., Pellens, M. (2014). Who makes, who breaks: Which scientists stay in academe? Economics Letters, 122(2), 229-232.

Baum, J.A.C., Dahlin, K.B. (2007). Aspiration Performance and Railroads' Patterns of Learning from Train Wrecks and Crashes. Organization Science, 18(3), 368-385. 
Berbegal-Mirabent, J., Lafuente, E., Solé, F. (2013). The pursuit of knowledge transfer activities: An efficiency analysis of Spanish universities. Journal of Business Research, 66(10), 2051-2059.

Caldera, A., Debande, O. (2010). Performance of Spanish universities in technology transfer: An empirical analysis. Research Policy, 39(9), 1160-1173.

Caves, D.W., Christensen, L.R., Diewert, W.E. (1982). The Economic Theory of Index Numbers and the Measurement of Input, Output, and Productivity. Econometrica, 50, 13931414.

Chambers, R.G., Pope, R.D. (1996). Aggregate productivity measures. American Journal of Agricultural Economics, 78(5), 1360-1365.

Chapple, W., Lockett, A., Siegel, D., Wright, M. (2005). Assessing the relative performance of UK university technology transfer offices: parametric and non-parametric evidence. Research Policy, 34(3), 369-384.

Chen, M.-J., Miller, K. (2007). Competitive Tension: The Awareness-Motivation-Capability Perspective. Academy of Management Journal, 50(1), 101-118.

Clarysse, B., Wright, M., Lockett, A., Van de Velde, E., Vohora, A. (2005). Spinning out new ventures: A typology of incubation strategies from European research institutions. Journal of Business Venturing, 20, 183-216.

Cooper, W.W., Seiford, L.M., Zhu, J. (2011). Handbook on data envelopment analysis, second edition. New York: Springer.

Di Gregorio, D., Shane, S. (2003). Why do some universities generate more start-ups than others? Research Policy, 32, 209-227.

Dill, D.D. (2014). Public policy design and university reform: Insights into academic change. In C. Musselin and P.N. Teixeira (Eds.), Reforming Higher Education (pp. 21-37). Netherlands: Springer.

Etzkowitz, H., Webster, A., Gebhardt, C., Terra, B.R.C. (2000). The future of the university and the university of the future: evolution of ivory tower to entrepreneurial paradigm. Research Policy, 29, 313-330.

European Commission (2015). Annual Report on the ERC activities and achievements in 2014. Publications Office of the European Union, Luxembourg.

Färe, R., Grosskopf, S., Lindgren, B., Roos, P. (1989). Productivity developments in Swedish hospitals: A Malmquist output index approach. In A. Charnes, W.W. Cooper, A.Y. Lewin, and L. Seiford (Eds.), Data envelopment analysis: Theory, methodology, and applications (pp. 253-272). Netherlands: Springer.

Fitzgerald, C., Cunningham, J. A. (2016). Inside the university technology transfer office: mission statement analysis. Journal of Technology Transfer, 41(5), 1235-1246. 
Friedman, J., Silberman, J. (2003). University technology transfer: do incentives, management, and location matter? Journal of Technology Transfer, 28(1), 17-30.

Greene, W. (2003). Econometric Analysis, fifth edition. Upper Saddle River, NJ: Prentice Hall.

Greve, H.R. (1998). Performance, aspirations, and risky organizational change. Administrative Science Quarterly, 43(1), 58-86.

Grifell-Tatjé, E., Lovell, C.A.K. (1999). Profits and productivity. Management Science, 45(9), 1177-1193.

Grifell-Tatjé, E., Lovell, C.A.K. (2015). Productivity Accounting: The Economics of Business Performance. New York: Cambridge University Press.

Guerrero, M., Urbano, D. (2012). The development of an entrepreneurial university. Journal of Technology Transfer, 37(1), 43-74.

Hausman, J. (1978). Specification Tests in Econometrics. Econometrica, 46, 1251-1271.

Hsu, D.W., Shen, Y.C., Yuan, B.J., Chou, C.J. (2015). Toward successful commercialization of university technology: Performance drivers of university technology transfer in Taiwan. Technological Forecasting and Social Change, 92, 25-39.

Iyer, D.N., Miller, K.D. (2008). Performance Feedback, Slack, and the Timing of Acquisitions. Academy of Management Journal, 51(4), 808-822.

Kahneman, D., Tversky, A. (1979). Prospect theory: Analysis of decision under risk. Econometrica, 47(2), 263-292.

Kim, Y. (2013). The ivory tower approach to entrepreneurial linkage: productivity changes in university technology transfer. Journal of Technology Transfer, 38(2), 180-197.

Kumar, S., Russell, R.R. (2002). Technological change, technological catch-up, and capital deepening: relative contributions to growth and convergence. American Economic Review, 92(3), 527-548.

Labianca, G., Fairbank, J.F., Andrevski, G., Parzen, M. (2009). Striving toward the future: aspiration - performance discrepancies and planned organizational change. Strategic Organization, 7(4), 433-466.

Lafuente, E., Berbegal-Mirabent, J. (2017). Contract employment policy and research productivity of knowledge workers: an analysis of Spanish universities. International Journal of Human Resource Management, in press, doi: http://dx.doi.org/10.1080/09585192.2017.1323226.

Levinthal, D.A., March, J.G. (1981). A Model of Adaptive Organizational Search. Journal of Economic Behavior and Organization, 2(4), 307-333.

Levitt, B., March, J. (1988). Organizational Learning. Annual Review of Sociology, 14, 319-340. Macho-Stadler, I., Pérez-Castrillo, D., Veugelers, R. (2007). Licensing of university inventions: The role of a technology transfer office. International Journal of Industrial Organization, 25(3), 483-510. 
Malmquist, S. (1953). Index numbers and indifference surfaces. Trabajos de Estadística, 4(2), 209-242.

Perkmann, M., Tartari, V., McKelvey, M., Autio, E., Broström, A., D’Este, P., Fini, R., Geuna, A., Grimaldi, R., Hughes, A. and Krabel, S. (2013). Academic engagement and commercialisation: A review of the literature on university-industry relations. Research Policy, 42(2), 423-442.

Perkmann, M., Walsh, K. (2009). The two faces of collaboration: impacts of university-industry relations on public research. Industrial and Corporate Change, 18(6), 1033-1065.

Podinovski, V.V., Thanassoulis, E. (2007). Improving discrimination in data envelopment analysis: Some practical suggestions. Journal of Productivity Analysis, 28 (1-2), 117-126.

Sellenthin, M.O. (2009). Technology transfer offices and university patenting in Sweden and Germany. Journal of Technology Transfer, 34(6), 603-620.

Sengupta, J.K. (1987). Efficiency measurement in non-market systems through data envelopment analysis. International Journal of Systems Science, 18(12), 2279-2304.

Shane, S. (2002). Selling university technology: Patterns from MIT. Management Science, 48(1), 122-137.

Shattock, M. (2009). Entrepreneurialism and organizational change in higher education. In M. Shattock (Ed.), Entrepreneurialism in universities and the knowledge economy (pp. 1-8). Maidenhead: Society for Research into Higher Education and Open University Press.

Siegel, D.S., Veugelers, R., Wright, M. (2007). Technology transfer offices and commercialization of university intellectual property: performance and policy implications. Oxford Review of Economic Policy, 23(4), 640-660.

Siegel, D.S., Waldmann, D.A., Link, A.N. (2003). Assessing the impact of organisational practices on the productivity of university technology transfer offices: an exploratory study. Research Policy, 32(1), 27-48.

Thanassoulis, E., Portela, M.C.S., Despic, O. (2008). DEA — the mathematical programming approach to efficiency analysis. In H. Fried, C.A.K. Lovell, and S. Schmidt, S. (Eds.), The measurement of productive efficiency and productivity growth (pp. 251-420). New York: Oxford University Press.

Thursby, J.G., Kemp, S. (2002). Growth and productive efficiency of university intellectual property licensing. Research Policy, 31(1), 109-124.

Thursby, J.G., Thursby, M.C. (2002). Who is selling the ivory tower: sources of growth in university licensing. Management Science, 48(1), 90-104.

Vinig, T., Lips, D. (2015). Measuring the performance of university technology transfer using meta data approach: the case of Dutch universities. Journal of Technology Transfer, 40(6), 1034-1049. 
Wooldridge, J. (2002). Econometric Analysis of Cross Section and Panel Data. Cambridge, MA: MIT Press.

Wright, M., Siegel, D.S., Lockett, A. (2007). The rise of entrepreneurial activity at universities: Organizational and societal implications. Industrial and Corporate Change, 16(4), 489-504. 


\section{List of Figures}

Figure 1. Productivity results: Malmquist TFP index

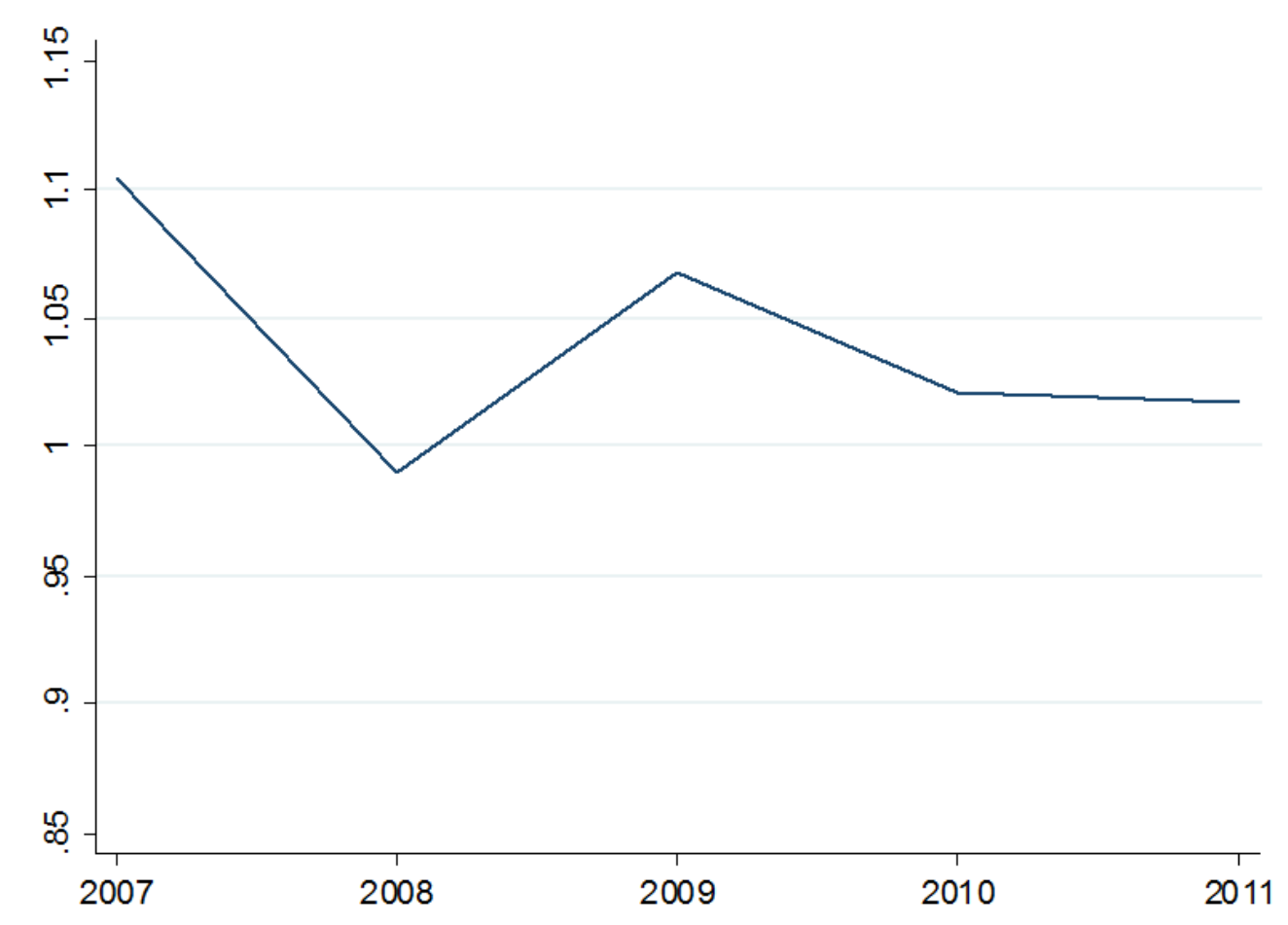

Source: Authors' elaboration.

Figure 2. Operating efficiency and technical change

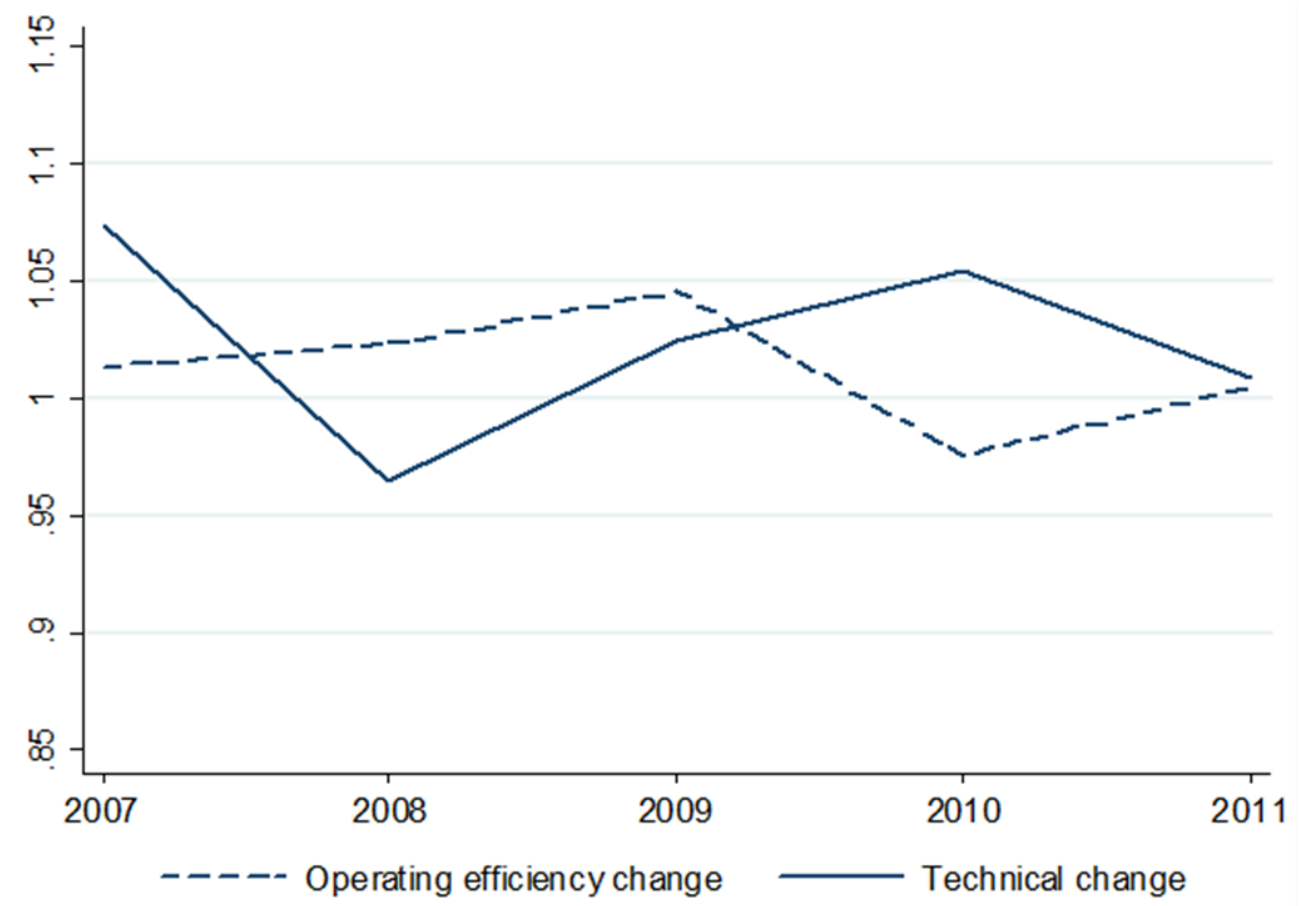

Source: Authors' elaboration. 
Figure 3. The relationship between aspiration performance and total factor productivity

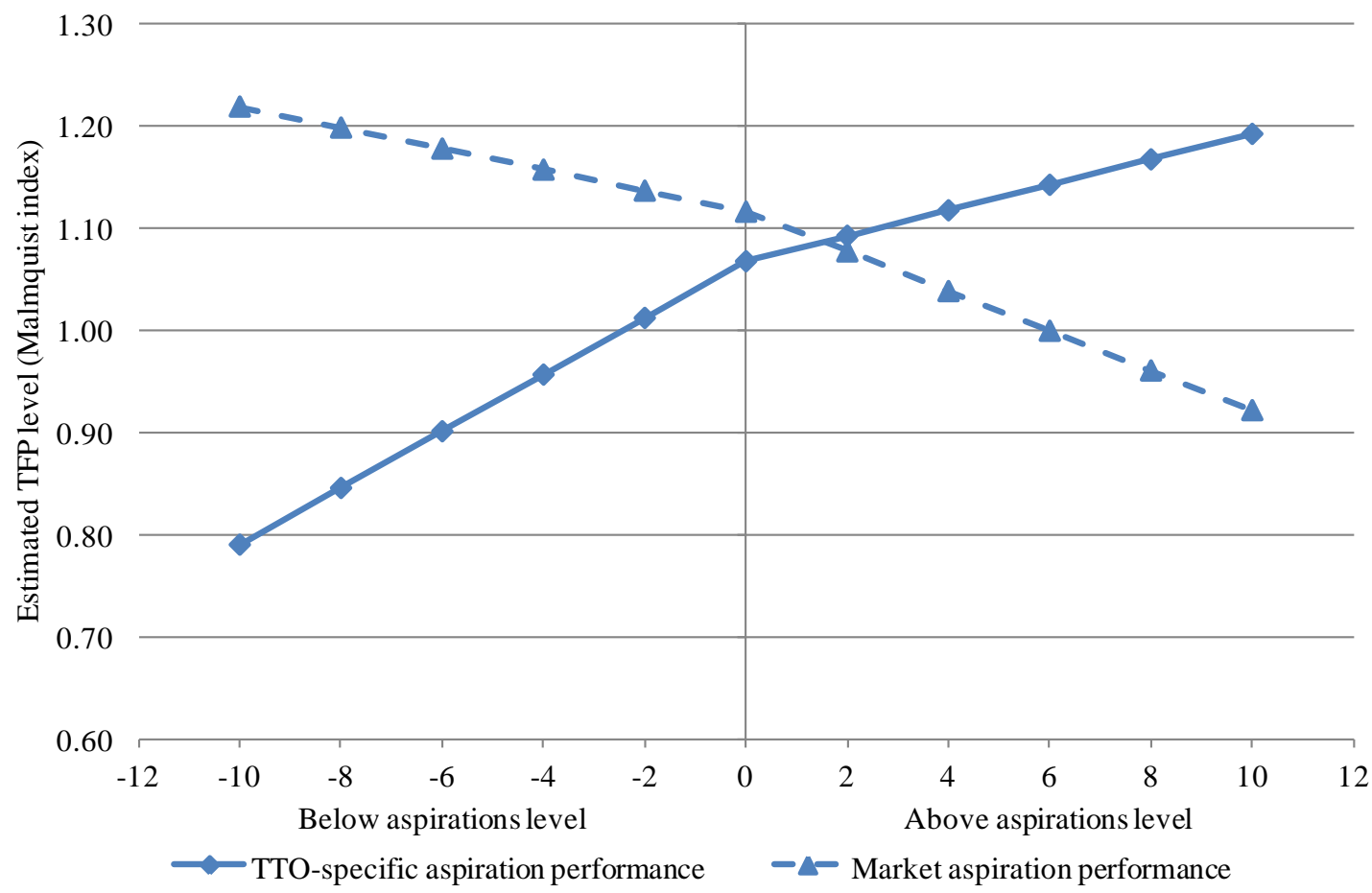

Source: Authors' elaboration 


\section{List of Tables}

Table 1. Technology transfer efficiency of Spanish public TTOs: Descriptive statistics for the input-output set

\begin{tabular}{|l|c|c|c|c|}
\hline & Mean & Std. dev. & Minimum & Maximum \\
\hline Inputs & & & & \\
\hline$(\mathbf{x} 1)$ Faculty & 2132.54 & 1299.38 & 446 & 7539 \\
\hline$(\mathbf{x} 2)$ TTO technology-transfer staff & 2.61 & 1.81 & 1 & 11 \\
\hline$(\mathbf{x 3})$ TTO administrative staff & 12.49 & 12.61 & 1 & 92 \\
\hline & & & & \\
\hline Outputs & & & & \\
\hline$(\mathbf{y} 1)$ Spinoffs & 2.68 & 3.57 & 0 & 22 \\
\hline$(\mathbf{y} 2)$ Patents & 6.53 & 7.46 & 0 & 47 \\
\hline$(\mathbf{y} 3)$ Licenses & 4.34 & 7.10 & 0 & 72 \\
\hline
\end{tabular}

Number of observations: 264 (44 observations during 2006-2011).

Table 2. Technology transfer efficiency of Spanish public TTOs: Descriptive statistics for the input-output set between 2006 and 2011

\begin{tabular}{|l|l|l|l|l|l|l|}
\hline & $\begin{array}{l}\mathbf{x 1 :} \\
\text { Faculty }\end{array}$ & $\begin{array}{l}\mathbf{x 2 :} \\
\text { TTO } \\
\text { technology- } \\
\text { transfer staff }\end{array}$ & $\begin{array}{l}\text { x3: } \\
\text { TTO } \\
\text { administrative } \\
\text { staff }\end{array}$ & $\begin{array}{l}\text { y1: } \\
\text { Spinoffs }\end{array}$ & $\begin{array}{l}\text { y2: } \\
\text { Patents }\end{array}$ & $\begin{array}{l}\text { y3: } \\
\text { Licenses }\end{array}$ \\
\hline 2006 & 1988.26 & 2.10 & 12.44 & 3.41 & 4.27 & 4.32 \\
\hline 2007 & 2031.20 & 2.35 & 12.30 & 2.70 & 4.82 & 4.23 \\
\hline 2008 & 2078.07 & 2.59 & 12.82 & 2.36 & 4.80 & 3.84 \\
\hline 2009 & 2124.93 & 2.61 & 13.08 & 2.61 & 6.02 & 3.98 \\
\hline 2010 & 2249.91 & 2.82 & 11.72 & 2.73 & 9.50 & 4.64 \\
\hline 2011 & 2322.89 & 3.18 & 12.55 & 2.27 & 9.80 & 5.02 \\
\hline Total & 2132.54 & 2.61 & 12.49 & 2.68 & 6.53 & 4.34 \\
\hline
\end{tabular}

Number of observations: 264 (44 observations during 2006-2011).

Table 3. Descriptive statistics for the selected variables (2006-2011)

\begin{tabular}{|l|c|c|c|c|}
\hline & Mean & Std. dev. & Minimum & Maximum \\
\hline $\begin{array}{l}\text { Configuration of the technology transfer } \\
\text { portfolio }\end{array}$ & 32.35 & 6.17 & 11.91 & 41.46 \\
\hline $\begin{array}{l}\text { TTO-specific aspiration performance } \\
\left(\mathrm{AP}^{\mathrm{TTO}}\right)\end{array}$ & 2.45 & 5.47 & -17.56 & 14.95 \\
\hline Market aspiration performance (AP & & & \\
\hline TTOT $)$ & 0.82 & 5.08 & -16.55 & 7.15 \\
\hline TTO age (years) & 15.09 & 13.46 & 3 & 94 \\
\hline University size (faculty) & 18.00 & 4.00 & 5 & 28 \\
\hline University age (years) & $2,161.40$ & $1,314.47$ & 446 & 7.539 \\
\hline Science park & 141.34 & 224.33 & 10 & 793 \\
\hline Polytechnic university & 0.66 & 0.47 & 0 & 1 \\
\hline
\end{tabular}

Number of observations: 264 (44 observations during 2006-2011). 
Table 4. Malmquist TFP index: Results

\begin{tabular}{|l|c|c|c|}
\hline & $\begin{array}{l}\text { Malmquist index } \\
(\mathrm{TFP})\left(M\left(x_{t}, y_{t}, x_{t+1}, y_{t+1}\right)\right)\end{array}$ & $\begin{array}{l}\text { Technical } \\
\text { change }(\Delta T E)\end{array}$ & $\begin{array}{l}\text { Technological } \\
\text { change }(\Delta T C)\end{array}$ \\
\hline 2007 & 1.1040 & 1.0134 & 1.0733 \\
\hline 2008 & 0.9892 & 1.0234 & 0.9642 \\
\hline 2009 & 1.0684 & 1.0456 & 1.0254 \\
\hline 2010 & 1.0213 & 0.9758 & 1.0546 \\
\hline 2011 & 1.0173 & 1.0052 & 1.0095 \\
\hline Total & 1.0400 & 1.0127 & 1.0254 \\
\hline
\end{tabular}

Number of observations: 220 (44 observations during 2007-2011).

Table 5. Regression results: The relationship between aspiration performance and technology transfer productivity

\begin{tabular}{|c|c|c|}
\hline & Model 1 & Model 2 \\
\hline $\begin{array}{l}\text { TTO-specific aspiration performance } \\
\left(\mathrm{AP}^{\mathrm{TTO}}\right)\end{array}$ & $0.0164(0.0061)^{* * *}$ & \\
\hline Market aspiration performance $\left(\mathrm{AP}^{\mathrm{MKT}}\right)$ & $-0.0061(0.0067)$ & \\
\hline $\begin{array}{l}\text { TTO-specific aspiration performance } \\
\left(\mathrm{AP}^{\mathrm{TTO}}\right)<0\end{array}$ & & $0.0278(0.0096)^{* * *}$ \\
\hline $\begin{array}{l}\text { TTO-specific aspiration performance } \\
\left(\mathrm{AP}^{\mathrm{TTO}}\right)>0\end{array}$ & & $0.0126(0.0073)^{*}$ \\
\hline Market aspiration performance $\left(\mathrm{AP}^{\mathrm{MKT}}\right)<0$ & & $-0.0075(0.0128)$ \\
\hline Market aspiration performance $\left(\mathrm{AP}^{\mathrm{MKT}}\right)>0$ & & $-0.0103(0.0048)^{* *}$ \\
\hline University size (ln faculty) & $-0.0112(0.0059)^{*}$ & $-0.0114(0.0067)^{*}$ \\
\hline University age (ln years) & $-0.0085(0.0195)$ & $-0.0130(0.0191)$ \\
\hline TTO size (ln total staff) & $-0.0262(0.0490)$ & $-0.0218(0.0115)$ \\
\hline TTO age (ln years) & $0.0718(0.0990)$ & $0.0746(0.1036)$ \\
\hline Science park & $0.0731(0.0598)$ & $0.0682(0.0618)$ \\
\hline Polytechnic university & $0.0912(0.0481)^{*}$ & $0.0867(0.0509)^{*}$ \\
\hline Time dummies & Yes & Yes \\
\hline Regional dummies & Yes & Yes \\
\hline Intercept & $0.8786(0.3903)^{* *}$ & $0.8435(0.3794)^{* *}$ \\
\hline Wald test (chi2) & $47.67 * * *$ & $48.43 * * *$ \\
\hline R2 (overall) & 0.1254 & 0.1296 \\
\hline Hausman specification test & $4.97(p=0.89)$ & $6.95(p=0.86)$ \\
\hline Average VIF (minimum - maximum) & $2.66(1.32-6.89)$ & $2.77(1.33-7.91)$ \\
\hline Observations & 220 & 220 \\
\hline
\end{tabular}

Robust standard errors are presented in brackets. *, **, *** indicate significance at the $10 \%, 5 \%$ and $1 \%$, respectively. 


\section{Appendix}

Table A1. Malmquist TFP results of Spanish public technology transfer offices (2007-2011)

\begin{tabular}{|c|c|c|c|c|c|}
\hline $\mathrm{N}$ & Technology Transfer Office & $\begin{array}{l}\text { Average } \\
\text { TFP }\end{array}$ & $\mathrm{N}$ & Technology Transfer Office & $\begin{array}{l}\text { Average } \\
\text { TFP }\end{array}$ \\
\hline 1 & Universidad de Almería & 1.1728 & 23 & $\begin{array}{l}\text { Universitat Politècnica de } \\
\text { Catalunya }\end{array}$ & 1.1023 \\
\hline 2 & Universidad de Cádiz & 0.9545 & 24 & Universitat Pompeu Fabra & 0.9296 \\
\hline 3 & Universidad de Córdoba & 1.1583 & 25 & Universitat Rovira i Virgili & 1.0613 \\
\hline 4 & Universidad de Granada & 1.0628 & 26 & Universidad de Alicante & 1.0673 \\
\hline 5 & Universidad de Huelva & 1.1588 & 27 & Universitat Jaume I & 0.9575 \\
\hline 6 & Universidad de Jaén & 0.9086 & 28 & $\begin{array}{l}\text { Universidad Miguel } \\
\text { Hernández }\end{array}$ & 1.2476 \\
\hline 7 & Universidad de Málaga & 1.0542 & 29 & $\begin{array}{l}\text { Universitat Politècnica de } \\
\text { Valencia }\end{array}$ & 0.8764 \\
\hline 8 & $\begin{array}{l}\text { Universidad Pablo de } \\
\text { Olavide (Sevilla) }\end{array}$ & 1.0744 & 30 & $\begin{array}{l}\text { Universitat de Valencia } \\
\text { Estudi General }\end{array}$ & 1.0395 \\
\hline 9 & Universidad de Sevilla & 1.0457 & 31 & $\begin{array}{l}\text { Universidad de } \\
\text { Extremadura }\end{array}$ & 0.8676 \\
\hline 10 & Universidad de Zaragoza & 0.9492 & 32 & Universidad de la Coruña & 1.0738 \\
\hline 11 & Universidad de Oviedo & 0.9316 & 33 & $\begin{array}{l}\text { Universidade de Santiago } \\
\text { de Compostela }\end{array}$ & 1.0842 \\
\hline 12 & Universitat Illes Balears & 0.8988 & 34 & Universidade de Vigo & 1.0423 \\
\hline 13 & Universidad de La Laguna & 0.9582 & 35 & $\begin{array}{l}\text { Universidad de Alcalá de } \\
\text { Henares }\end{array}$ & 0.8733 \\
\hline 14 & Universidad de Cantabria & 0.9030 & 36 & $\begin{array}{l}\text { Universidad Autónoma de } \\
\text { Madrid }\end{array}$ & 0.9402 \\
\hline 15 & $\begin{array}{l}\text { Universidad Castilla-La } \\
\text { Mancha }\end{array}$ & 0.9202 & 37 & $\begin{array}{l}\text { Universidad Carlos III de } \\
\text { Madrid }\end{array}$ & 1.1497 \\
\hline 16 & Universidad de Burgos & 0.8821 & 38 & $\begin{array}{l}\text { Universidad Complutense } \\
\text { de Madrid }\end{array}$ & 1.3063 \\
\hline 17 & Universidad de Salamanca & 1.0026 & 39 & $\begin{array}{l}\text { Universidad Politécnica de } \\
\text { Madrid }\end{array}$ & 1.3581 \\
\hline 18 & Universidad de Valladolid & 0.9802 & 40 & $\begin{array}{l}\text { Universidad Rey Juan } \\
\text { Carlos }\end{array}$ & 0.9886 \\
\hline 19 & $\begin{array}{l}\text { Universitat Autónoma de } \\
\text { Barcelona }\end{array}$ & 1.0237 & 41 & Universidad de Murcia & 1.1727 \\
\hline 20 & Universitat de Barcelona & 1.0156 & 42 & $\begin{array}{l}\text { Universidad Pública de } \\
\text { Navarra }\end{array}$ & 1.2459 \\
\hline 21 & Universitat de Girona & 0.9986 & 43 & $\begin{array}{l}\text { Universidad del País } \\
\text { Vasco/ Euskal Herriko } \\
\text { Unibertsitatea }\end{array}$ & 0.9851 \\
\hline 22 & Universitat de Lleida & 0.9120 & 44 & Universidad de La Rioja & 0.9264 \\
\hline
\end{tabular}

Note: The column 'Average TFP' is the Malmquist total factor productivity (TFP) index computed from equation (2). Average values between 2007 and 2011 are presented in the table. 